\title{
FUNDAMENTOS DA LIBERDADE E DO DIREITO EM HEGEL
}

\section{Daniel Rocha Chaves*1 \\ Luiz Henrique U. Cademartori**}

RESUMO: A presente pesquisa tem como propósito explorar os fundamentos da liberdade e do direito na obra de Georg W. F. Hegel. Para tanto, levanta-se a hipótese de que a liberdade é condicionada pela existência do direito, relacionando-se de maneira interdependente e que, dentro de um projeto de modernidade, as três etapas do Espírito Objetivo são necessárias para se atingir a plena efetivação da liberdade. Metodologicamente trata-se de uma pesquisa qualitativa fazendo-se valer do método indutivo e, quanto à sua finalidade, é uma pesquisa de cunho exploratória e explicativa.

Palavras-chave: Espírito Objetivo; Filosofia do Direito; Hegel; Liberdade; Modernidade.

\section{FOUNDATIONS OF FREEDOM AND LAW IN HEGEL}

Abstract: The purpose of this research is to explore the foundations of freedom and law in the work of Georg W. F. Hegel. To do so, it raises the hypothesis that freedom is conditioned by the existence of law, relating itself in an interdependent way and that, within a project of modernity, the three stages of the Objective Spirit are necessary to achieve the full realization of freedom. Methodologically, it is a qualitative research making use of the inductive method and, as for its purpose, it is an exploratory and explanatory research.

Keywords: Objective Spirit; Philosophy of Right; Hegel; Freedom; Modernity.

\section{INTRODUÇÃO}

A modernidade, enquanto momento histórico, social e filosófico, possui uma peculiaridade que as demais eras do desenvolvimento humano não eram capazes de albergar em sua formulação: a propriedade de formular críticas e, ao mesmo tempo, ser alvo de críticas e adaptar-se ou reagir às apreciações feitas à sua concepção, gênese, estrutura ou andamento. Hodiernamente, parte da teoria crítica vem tecendo, com muito esmero e propriedade, considerações à modernidade, trazendo à vista aspectos obscuros que eram despercebidos e, muitas vezes, propositalmente ignorados por aqueles que estavam cegos pelas luzes do então aclamado esclarecimento, valendo uma menção especial às pesquisas que envolvem as temáticas da decolonialidade e pós-colonialidade.

* Doutorando em Direito pelo Programa de Pós-Graduação em Direito da Universidade Federal de Santa Catarina (PPGD/UFSC). Bolsista do CNPq. E-mail: dan_chaves@ hotmail.com

** Professor do Programa de Pós-Graduação em Direito da Universidade Federal de Santa Catarina (PPGD/UFSC). Doutor em Direito pelo PPGD/UFSC com estágio pós-doutoral na Universidade de Granada (Espanha). E-mail: luiz.cademartori@gmail.com

CONPEDI LAW REVIEW | EVENTO VIRTUAL | v. 6 | n. 1 | p. 118 - 137 | JAN - DEZ | 2020 
Uma defesa da modernidade não pode ser feita sem apontar vários pontos de tensão atinentes a tal marco histórico; e não se está aqui a falar do sangue da nobreza, fruto do trabalho incessante das guilhotinas que inundou a hoje assim chamada Praça da Revolução em Paris. Também não está se remetendo ao Período do Terror, capitaneado por Maximilien de Robespierre, que vitimou todos aqueles que pudessem ser vistos como contrários aos auspícios da revolução e que ao fim deu cabo de seu próprio líder.

Um dos pontos obscuros que se quer ressaltar aqui, a título de exemplo, é a ambiguidade em torno do tratamento da escravidão. Enquanto o ideal da liberdade era alçado como um dos baluartes da Revolução Francesa, os fluxos da escravidão cruzavam o Oceano Atlântico de forma tão retumbante, por conta do volume e impacto nas economias, quanto despercebida, visto que os passageiros - não-voluntários, a bem da verdade - não possuíam personalidade jurídica para serem alvos dos direitos reivindicados por aqueles que acabaram de depor o ancien régime.

O exemplo citado pode ser reverberado a partir da constatação de Susan Buck-Morss em seu artigo intitulado "Hegel e o Haiti" (2011). Nele a autora aborda como a questão da escravidão, especificamente a dos povos negros, ficou à margem das preocupações dos pensadores que pertencem à idiossincrasia iluminista, exaltando os feitos liberais e revolucionários da revolução pela independência das 13 Colônias, por exemplo. Como contrapartida, Buck-Morss, fazendo-se valer do trabalho de Louis Sala-Molins, relata como a Revolução Haitiana foi um acontecimento sem precedentes dentro do contexto escravagista vigente, no qual o povo subjugado pela colônia acabou conquistando sua liberdade, indo de encontro ao status quo. Não é despiciendo falar que as colônias eram um dos sustentáculos da França e da própria vigência dos auspícios revolucionários, que dependiam dos mantimentos arrematados das colônias.

Mais adiante se tem o cerne do problema proposto por Susan Buck-Morss: correlacionar o antagonismo dos ideais de liberdade da Revolução Francesa com a prática da escravidão, tendo como mote a "dialética do senhor e do escravo" elaborada por G. W. F. Hegel em sua obra "Fenomenologia do Espírito" (Cf. 1977, p.111). Em resumo, Buck-Morss faz um hercúleo trabalho historiográfico e filosófico para convergir os ideais de liberdade do jovem Hegel em Jena, trespassando por escritos mais tardios, com o que estava acontecendo na então colônia de São Domingos. 
Os ideais de liberdade dispostos nos escritos de Hegel e citados por Buck-Morss (147-149) são um dos motes para a problemática do artigo que se pretende desenvolver. Isto por que a concepção de liberdade que Hegel se faz valer acaba por destoar do que os filósofos liberais que o precederam haviam sustentado.

Voltado para uma perspectiva filosófico-social, Hegel viu nas instituições surgidas sob o sob o vaticínio da Revolução Francesa a possibilidade de desenvolvimento da liberdade e, por mais contraditório que possa aparentar pelo que foi relatado até então. Utilizando o próprio vernáculo hegeliano, Hegel vislumbrou os idos da Revolução Francesa como o móbil para o desenvolvimento da liberdade e, por conseguinte, do espírito.

A liberdade, dentro do âmbito hegeliano, não é um acontecimento repentino ou simplesmente uma dimensão negativa dos impulsos externos que podem agir sobre um indivíduo. Conforme já foi dito, a liberdade se realiza na Família, nas instituições da Sociedade Civil e no Estado e, para tanto, necessita de substrato material para ser consolidada.

Destarte, o presente trabalho tem como problemática a seguinte pergunta: como se dá o desenvolvimento e os fundamentos da liberdade soba égide da filosofia e do sistema filosófico elaborado por Hegel? Ademais, como se dá o papel do direito em meio a esse projeto filosófico e qual é a sua relação com o propósito da liberdade?

A hipótese elaborada é de que a liberdade é condicionada pela existência do direito, relacionando-se de maneira interdependente e que, dentro de um projeto de modernidade, as três etapas do Espírito Objetivo hegeliano (Direito Abstrato, Moralidade e Eticidade) são necessárias para se atingir a plena efetivação da liberdade, trazendo para uma perspectiva contemporânea, na realização do estado democrático de direito.

Dessa forma, tem-se como principal objetivo da pesquisa ora empreitada explorar como a liberdade se desdobra por entre as etapas do projeto filosófico elaborado por Hegel. Para a realização dessa tarefa serão percorridas três etapas que serão melhor descritas a seguir.

Em um primeiro momento será exposto, sob o título de Prólogo da liberdade em Hegel, como o projeto da modernidade está relacionado com a ideia de liberdade. Para tanto, faz-se valer de Habermas, primeiramente, para depois adentrar diretamente nos escritos de e sobre Hegel. Ao longo dessa primeira parte também haverá alguns esclarecimentos sobre as intenções e sobre a linguagem hegeliana. CONPEDI LAW REVIEW | EVENTO VIRTUAL | v. 6 | n. 1 | p. 118 - 137 | JAN - DEZ | 2020 
No segundo tópico serão tratados, conforme consta no título, dos desdobramentos do Espírito, sendo Espírito o termo utilizado por Hegel para designar o conjunto das realizações humanas. Para tanto, será explanado o sistema filosófico desenvolvido por Hegel, tomando como principal referência a obra Enciclopédia das Ciências Filosóficas. Nela se vê o projeto hegeliano divido em três partes: Ciência da Lógica, Filosofia da Natureza e Filosofia do Espírito. Esta última parte receberá mais atenção uma vez que é nela que está contida a Filosofia do Direito, objeto central do presente trabalho.

Passadas as explicações sobre o sistema hegeliano, atinge-se o ponto nevrálgico para a presente pesquisa, a saber, a Filosofia do Direito, que será tratada no terceiro tópico desta pesquisa. É na Filosofia do Direito em que estão contidos os fundamentos da filosofia prática de Hegel.

Como um desdobramento do terceiro tópico, o derradeiro ponto abordará a Eticidade, última parte do Espírito Objetivo e, consequentemente, da Filosofia do Direito. É nela que se pode vislumbrar de maneira mais concreta como a liberdade toma forma nas instituições, a saber, na Família, na Sociedade Civil e no Estado.

A justificativa para a presente investigação se dá, em um primeiro momento, pelo investimento em tornar-se um pouco menos densas as ideias daquele que é tipo por muitos como um dos filósofos mais herméticos. No contexto social em que estamos inseridos também é relevante mostrar como a liberdade, aos moldes de Hegel, é elemento determinante para a subsistência da sociedade.

Por fim, a título de excerto, no ano da elaboração deste artigo, Georg W. F. Hegel completa 250 e sua obra "Linhas Fundamentais da Filosofia do Direito ou direito natural e ciência do estado em compêndio", mais conhecida por Filosofia do Direito de Hegel, completa 200 anos de publicação. Destarte, por sua relevância no cenário filosófico e sociológico, julgou-se pertinente intentar uma investigação em que o pensamento hegeliano figurasse no proscênio, mesmo em um âmbito modesto que é a presente pesquisa.

No que se refere ao âmbito metodológico, trata-se de uma pesquisa qualitativa fazendo-se valer do método indutivo e, quanto à sua finalidade, é uma pesquisa de cunho exploratória e explicativa. 


\section{PRÓLOGO À LIBERDADE EM HEGEL}

O conceito de modernidade utilizado na presente pesquisa tem como fundamento o que Hegel vem a empregar e entender por modernidade. Para tal fulcro, Jürgen Habermas (2000, p. 9) faz uma história do conceito de modernidade, bebendo da metodologia elaborada por Reinhart Koselleck, para verificar como se deu o emprego do termo por parte de Hegel.

É a partir desse diapasão histórico que Habermas começa a reconstruir a ideia e o projeto da modernidade. Diferentemente de outros tempos, na modernidade há a peculiaridade de se poder tecer expectativas em relação ao futuro. Hegel é claro na introdução à Fenomenologia do Espírito (1977, p. 6) quando diz que não é difícil perceber que o tempo em que estamos situados (no caso de Hegel, o florescimento da modernidade) é um período de nascimento e transição para uma nova era na qual o espírito rompeu com o mundo que até então havia habitado e necessário submergi-lo no passado e no trabalho de sua própria transformação.

Essas transformações que ocorrem dentro da modernidade tem por princípio a subjetividade que, segundo Habermas (2000, p. 25-26), é uma estrutura de auto-relação na qual o espírito se reconcilia consigo. Ademais, o significante do termo subjetividade pode ter quatro conotações diversas:

a) individualismo: no mundo moderno, a singularidade infinitamente particular pode fazer valer suas pretensões; b) direito de critica: o principio do mundo moderno exige que aquilo que deve ser reconhecido por todos se mostre a cada um como algo legitimo; c) autonomia da ação: é próprio dos tempos modernos que queiramos responder pelo que fazemos; d) por fim, a própria filosofia idealista: Hegel considera como obra dos tempos modernos que a filosofia apreenda a ideia que se sabe a si mesma.

Percebe-se que a subjetividade, no espectro hegeliano, é uma própria afirmação da liberdade do sujeito. A liberdade, portanto, é expressa por meio da vontade. Isso é mais bem percebido quando Hegel trata do que chamou de Moralidade. Esta, enquanto parte do Espírito Objetivo do sistema hegeliano ${ }^{2}$, aborda autodeterminação da vontade.

\footnotetext{
${ }^{2}$ Conforme lição de Henrique de Lima Vaz (1999 p. 376) "O Sistema, segundo Hegel, tem como alvo justamente demonstrar a identidade ou unidade do ser na diferença de suas manifestações, o que exige que a identidade abstrata inicial seja suprimida ao longo do movimento dialético que desdobra a pluralidade das manifestações na unidade concreta do Sistema".

CONPEDI LAW REVIEW | EVENTO VIRTUAL | v. 6 | n. 1 | p. 118 - 137 | JAN - DEZ | 2020 
A Moralidade é melhor explanada em duas obras, uma mais sistemática e outra mais propositiva: a Enciclopédia das Ciências Filosóficas (2005, p. 533) e a Filosofia do Direito (2010, p. 129), respectivamente. Enquanto a primeira expõe de forma ampla a pretensão filosófica do sistema elaborado por Hegel, dividindo-se em Ciência da Lógica, Filosofia da Natureza e Filosofia do Espírito; a Filosofia do Direito, não o direito propriamente dito, está localizada no centro da terceira parte da Enciclopédia, ou seja, quando se é tratado da Filosofia do Espírito.

Hegel já postula na Filosofia do Direito (2010, p. 129) que "o ponto de vista moral é o ponto de vista da vontade" e é no comentário ao parágrafo 106 que ele arremata a correlação da moralidade como dimensão da liberdade:

\begin{abstract}
A segunda esfera, a moralidade, apresenta por isso no todo o aspecto real do conceito de liberdade, e o processo dessa esfera consiste em suprassumir, segundo essa diferença em que mergulha a vontade, que inicialmente apenas sendo para si e que imediatamente apenas em si é idêntica com a vontade sendo em si ou universal, e a pô-la para si como idêntica com a vontade sendo em si. Esse movimento, segundo isso, é a elaboração do que agora é o terreno da liberdade, a subjetividade, a qual inicialmente é abstrata, isto é, diferente do conceito, toma-se igual a ele e, com isso, a ideia recebe sua verdadeira realização, que a vontade subjetiva se determina a ser igualmente objetiva e, com isso, verdadeiramente concreta.
\end{abstract}

Aqui cabe um adendo à expressão "suprassunção". Há um equivocado lugar comum de que a concepção dialética ${ }^{4}$ de Hegel se resume à tríade tese-antítese-síntese. Nos escritos de Hegel, porém, tal abordagem metodológica ocorre de modo diverso. Diferentemente dos gregos que concebiam a dialética como a arte do diálogo, Hegel fundamenta na dialética o próprio movimento e estrutura da realidade, o que vai além de ser uma mera questão procedimentalista.

Desta forma, Hegel dispõe a negação e, ao mesmo tempo, a reconciliação entre a universalidade abstrata e a particularidade concreta. Por universalidade e particularidade pode-se entender identidade e distinção, respectivamente (Cf. HEGEL, 2005, p. 249). É por meio dessa distinção que se chega a uma singularidade ${ }^{5}$ que nada mais é a inicialmente

\footnotetext{
${ }^{3} \mathrm{O}$ termo em alemão é o verbo aufheben e o substantivo Aufhebung, que foram traduzidos por Paulo Menezes na Fenomenologia do Espírito (1992) por suprassumir e suprassunção que em português literalmente significa superação ou negação.

${ }^{4}$ Por um esclarecimento direto de Hegel sobre sua concepção de dialética, sugere-se consultar o comentário ao parágrafo 31 da Filosofia do Direito (2010, p. 73-74).

${ }^{5}$ No parágrafo $7^{\circ}$ da Filosofia do Direito Hegel (1994, p. 129) explana o que vem a ser a Singularidade enquanto relação da Universalidade Abstrata com a Particularidade Concreta: "A vontade é a unidade desses dois momentos, - a particularidade refletida dentro de si e, por meio desta reflexão, reconduzida à CONPEDI LAW REVIEW | EVENTO VIRTUAL | v. 6 | n. 1 | p. 118 - 137 | JAN - DEZ | 2020 
referida suprassunção, o que seria o equivalente, dentro de um lugar comum, à síntese. Mais que uma superação, essa diferença implica numa reconciliação do universal e do particular e que se encontra mantido dentro do sistema.

Uma das alegorias utilizadas por Hegel para expressar essa dimensão da suprassunção está contida na introdução da Fenomenologia do Espírito (Cf. 1992, p. 20): a tensão entre o botão de flor e a própria flor. Para que possa desabrochar, o botão deve negar a sua própria condição, enquanto botão, para dar lugar ao novo, a flor. Mas para o desenlace do desabrochar, o botão de rosa também necessita se afirmar como elemento condicionante. A flor nega o botão, mas ao mesmo tempo o afirma. De maneira similar, o fruto que nascerá da flor a nega e a afirma, resultando numa contradição necessária. Não é a toa que Hegel é conhecido como o filósofo da necessidade.

\section{OS DESDOBRAMENTOS DO ESPÍRITO}

Anteriormente ao tratar da Moralidade, estava-se se referindo a uma parte específica do sistema elaborado por Hegel; sistema esse que pode ser visto de forma mais clara quando se debruça sobre a Enciclopédia das Ciências Filosóficas. De maneira sucinta, explana-se aqui como Hegel organizou a divisão do seu sistema filosófico.

A primeira parte é intitulada como Ciência da Lógica e seu título pode trazer alguns equívocos a um leitor desavisado, uma vez que a lógica em Hegel não diz respeito à lógica formal que se estuda desde a antiguidade clássica. Conforme Ramón Valls Plana (2005, p. 12), a Ciência da Lógica tem um perfil mais metafísico ou especulativo.

A segunda parte do sistema hegeliano se chama Filosofia da Natureza e comporta as observações que Hegel faz da apreensão que o homem fez das leis da natureza e da sua relação com a mesma (não em um sentido ecológico). Em resumo, o que está em questão na Filosofia da Natureza não é uma descrição da natureza, mas sim sua compreensão enquanto uma cadeia de estruturas racionais.

A terceira e derradeira parte, e para o propósito do presente trabalho também é a mais relevante, é a Filosofia do Espírito. Por espírito pode-se depreender o conjunto das

universalidade, - singularidade/ [ela é] a autodeterminação do eu, a um só tempo pôr-se como o negativo de si mesmo, isto é como determinado, restringido, e permanecer junto a si, isto é, em sua identidade consigo e em sua universalidade, e, assim, na determinação, encadear-se somente consigo mesmo". (Grifos do autor)

CONPEDI LAW REVIEW | EVENTO VIRTUAL | v. 6 | n. 1 | p. 118 - 137 | JAN - DEZ | 2020 
realizações humanas e para Hegel (Cf. 2005, p. 433) o conhecer do espírito é o mais concreto e, por conseguinte, a mais hercúlea das tarefas e se realizar.

O Espírito se desdobra em três etapas: Subjetivo, Objetivo e Absoluto. Por se tratar da parte que se requer mais atenção para o desenvolvimento da questão da liberdade no pensamento de Hegel, a explanação será um pouco mais detalhada que as demais, mas nos ateremos às primeiras e segundas dimensões do Espírito, visto que o Espírito Objetivo será exposto por último por ser onde estão contidos os principais fundamentos sobre a liberdade dentro de uma perspectiva institucional, que é o mote da pesquisa ora desenvolvida.

O Espírito Subjetivo é o estágio inicial da dimensão da liberdade, possui um caráter mais individual e divide-se em três partes: Antropologia - A alma; Fenomenologia do Espírito - A consciência; e Psicologia - O Espírito. Pode-se depreender que o Espírito Subjetivo está mais relacionado com as atividades atinentes ao sistema psíquico do serhumano. Ao fim dessa primeira parte Hegel trata d'O Espírito Livre, que é a suprassunção do Espírito Teórico e Prático, consistindo na reconciliação entre teoria e prática, indo além de uma mera superação. A vontade livre, portanto, é a singularidade que resulta dessa distinção e acaba por afirmar a sua liberdade (Cf. HEGEL,2005, p. 519).

A segunda etapa da Filosofia do Espírito é o Espírito Objetivo, que é a objetividade prática do que foi posto no Espírito Subjetivo, mas, como já foi mencionado, será tratado por último por questões metodológicas à estrutura da presente pesquisa. Portanto agora se dará atenção ao fim do sistema proposto por Hegel, a saber, o Espírito Absoluto.

De maneira categórica, Hegel (2005, p. 437) dispõe na Introdução à Filosofia do Espírito que o absoluto é o Espírito e esta é a definição suprema do absoluto e que perquirir essa definição foi a tendência absoluta de toda cultura e filosofia; sendo que a convergência dos esforços e ímpetos da religião e da ciência entorno desse conceito é que se pode conceber o que ele vem a chamar de história mundial.

Habermas (2000, p. 122), por seu turno, enfatiza que Hegel “concebe a razão como autoconhecimento reconciliador de um espírito absoluto" e que "o espírito absoluto passa impassivelmente sobre processo da história aberto ao futuro e sobre o caráter irreconciliado do presente". 
As etapas nas quais o Espírito Absoluto se desdobra são a Arte, a Religião Revelada e a Filosofia, respectivamente; o que implica que são nesses três estágios que o Espírito se reconcilia consigo. Conforme Hegel (2005, p. 581): "A consciência subjetiva do espírito absoluto é ela própria essencialmente um processo cuja unidade imediata e substancial é a crença no testemunho do espírito como uma certeza da verdade objetiva" (tradução nossa). Desta forma, ao atingir a verdade, o Espírito torna-se efetivo ${ }^{6}$, reconciliando as duas etapas finitas do Espírito, isto é, a subjetividade e a objetividade. Esta suprassunção, que é em-si e para-si numa relação circular infinita, é o Espírito em sua verdade absoluta, isto é: o Espírito Absoluto (Cf. HEGEL, 2005, p. 433).

Para concluir a Etapa do Espírito Absoluto, cita-se Henrique de Lima Vaz (1998, p. 120) ao afirmar que "[...] é no homem ou, mais propriamente, em sua intuição (Arte), em sua representação (Religião) e em seu conceito (Filosofia) que o Espírito se manifesta como absoluto [...]". (Grifos do autor)

Por fim, conforme já havia sido anunciado, tratar-se-á aqui da segunda etapa da Filosofia do Espírito, isto é, a o Espírito Objetivo, no qual está contido a Filosofia do Direito. É no Espírito Objetivo que se dá a externalidade do mundo, agindo como a negação do Espírito Subjetivo, que é referente a si mesmo. Nas palavras de Hegel (2005, p. 437), o Espírito Objetivo “(...) está na forma da realidade, como um mundo a ser produzido e que foi produzido a partir dele, e no qual a liberdade é como uma necessidade presente":

O Espírito Objetivo é a ideia absoluta, mas é apenas ser em-si; na medida em que o Espírito está assim no solo da finitude, sua racionalidade, que é de fato real, retém em si o aspecto da aparência externa. A vontade livre tem em primeiro lugar as [seguintes] distinções nela [isto é] que a liberdade é sua determinação interna e [seu] fim, e que se refere a uma objetividade externa previamente encontrada, que [por sua vez] se baseia no aspecto antropológico das necessidades particulares, isto é, nas coisas naturais externas que são para a consciência [por um lado], e na relação das vontades singulares com outras vontades [igualmente] singulares que são [cada uma delas] uma autoconsciência na medida em que são diferentes e particularizadas; este lado constitui o material externo para a existência da vontade. (Tradução nossa) (Grifos do autor)

\footnotetext{
${ }^{6}$ Ao se utilizar os termos efetivo e efetividade, deve-se salientar que eles possuem um lugar de destaque na filosofia hegeliana. Hegel tem uma semântica própria e para melhor compreensão dos seus escritos, o domínio dessa semântica se faz necessário. No original Hegel usa o adjetivo Wirklich, que literalmente significa "real". A partir do termo em alemão Hegel também emprega o e o substantivo Wirklichkeit. Contudo, em termos hegelianos as referidas expressões são traduzidas como efetivo (efetivamente real) e efetividade (realidade efetiva), respectivamente. Para melhor compreensão dessa questão linguística, recomenda-se a leitura da nota de rodapé número 1, redigida por Marcos Müller, tradutor da Introdução da obra "Linhas fundamentais da filosofia do direito ou direito natural e ciência do Estado em compêndio (1820)" (HEGEL, 1994, p. 109). 
Decompondo o trecho supracitado temos que, primeiramente, o Espírito Objetivo é um momento que está contido no absoluto, e isso pode ser percebido por que está inserido no solo da finitude, tendo em vista que só alcançará o infinito no momento do Espírito Absoluto.

Ainda ao fim da primeira frase também é perceptível que, diferentemente do Espírito Subjetivo que possui um arquétipo interno inerente à consciência psíquica, o Espírito Objetivo está voltado para a aparência externa. Não é à toa que a filosofia prática de Hegel está inserida nesta etapa.

Em seguida Hegel trata de forma direta da vontade livre destacando que a liberdade é sua forma e conteúdo, agindo de forma reflexiva, ou seja, a liberdade é a própria definição de vontade livre ao mesmo tempo em que também é a finalidade a ser perquirida pela mesma.

A vontade livre está voltada, nas palavras do autor, a uma objetividade externa, o que remete novamente, que o Espírito Objetivo é o que se dá na externalidade da subjetividade. Em seguida se vislumbra de forma mais clara como a vontade livre se manifesta numa perspectiva de filosofia prática, visto que ela, a vontade livre, parte das necessidades particulares relacionando-se com a consciência, em um primeiro momento; e com a relação de vontades singulares com outras vontades singulares.

Em outras palavras, corrobora-se com a explanação de Marcos L. Müller (2005, p. 161-162) sobre o Espírito Objetivo.

O espírito é denominado objetivo porque é concebido como a apresentação (Darstellung), precisamente, do processo pelo qual a sua determinação essencial, que é a liberdade ( $\mathrm{E} \S 382 ; \mathrm{FD} \S 4)$ - e aqui, mais precisamente, a liberdade em si e por si, concebida como unidade de inteligência e de vontade, como uma vontade intrinsecamente racional e universal (E § 481) - se objetiva e se configura "em direção à efetividade de um mundo", que se estrutura como "o sistema [racional] das determinações da liberdade", a qual, assim objetivada, "adquire a forma de necessidade" (E § 484; FD § 27). (Grifos do autor)

A partir dessa exposição do Espírito Objetivo, adentrar-se-á no seu detalhamento, expondo como se dá a sua tripartição, um estilo recorrente no sistema filosófico hegeliano, bem como essas etapas, a saber, Direito Abstrato, Moralidade e Eticidade são conteúdo e meio para a efetivação da liberdade.

\section{A FILOSOFIA DO DIREITO}


Publicada em 1820 (portanto, há exatos 200 anos da redação deste trabalho), as Linhas Fundamentais da Filosofia do Direito ou simplesmente Filosofia do Direito, são os esforços e reflexões de um Hegel já maduro que busca o enrijecimento do seu sistema filosófico.

O filósofo Rolf-Peter Horstmann (1999, p. 282) dispõe que caso lhe fosse pedido para sintetizar as principais características da Filosofia do Direito de Hegel, mais especificamente do que Hegel viria a chamar de mundo social, ele descreveria que o mundo social, conforme previsto por Hegel, corresponde a uma unidade orgânica em que todos os seus componentes são interdependentes, ou mutualmente dependentes uns dos outros, tendo em vista que a existência de cada elemento contribui para a existência de outros como uma relação reflexiva em cadeia. Tais componentes do mundo social acabam por consistir na multiplicidade de diferentes formas institucionalizadas de interação social, que juntas resultam naquilo que Hegel chama de vida ética.

Faz-se mister ressaltar que quando Hegel fala de direito, não se trata de uma concepção puramente jurídica. Já no parágrafo 486 da Enciclopédia (2005, p. 486-487) está disposto que o direito é a existência da vontade livre e que não se deve tomar o direito somente na limitação do sentido jurídico. Na concepção hegeliana o direito engloba "a existência de todas as determinações de liberdade". (Tradução nossa)

Ainda sobre essa concepção ampliada do que Hegel entende por direito, vale citar o que pensa Marcos Müller (2005, p. 162):

\footnotetext{
Trata-se de um conceito consideravelmente ampliado de direito, que não se restringe nem à sua validade normativa como ordenamento jurídico, nem às instituições da sua aplicação jurisdicional, pois ele é, antes de tudo, uma "efetividade imediata" (\$27) da liberdade objetivada, que no seu cerne lógico-especulativo resulta do processo de objetivação e de determinação completa do conceito de vontade livre em direção à Idéia (sic), concebida, por sua vez, como a "totalidade do seu sistema", isto é, a totalidade das determinações objetivas da liberdade na forma da necessidade.
}

Destarte, sanados eventuais equívocos sobre a dimensão semântica na qual Hegel se faz valer do termo "direito", pode-se passar para a análise da obra, propriamente dita.

Sobre o itinerário da Filosofia do Direito, Hegel, como de costume, divide em três partes: Direito Abstrato, que possui uma dimensão jurídica mais imediata, uma vez que trata de questões cíveis e penais, em especial o direito à propriedade, o contrato e a questão da 
coação e do crime; Moralidade, que já foi mencionada no início do presente trabalho; culminando da Eticidade, nas quais o ser humano desenvolve sua vida prática, a saber, na Família, na Sociedade Civil e no Estado.

Hegel (1994, p. 121) é categórico logo no início da sua Filosofia do Direito, uma vez que no quarto parágrafo ele dispõe o seguinte:

O solo do Direito é, em geral, o [elemento] espiritual e o seu lugar mais preciso e o seu ponto de partida [é] a vontade que é livre, de maneira que a liberdade constitui a substância e a sua determinação e que o sistema do direito é o reino da liberdade efetivada ${ }^{7}$ o mundo do espírito produzido a partir do próprio espírito como uma segunda natureza. (Grifo do autor em negrito) (Grifo nosso em itálico)

É relevante notar a relação entre o direito e a vontade livre. Pela passagem citada nota-se uma relação de interdependência entre ambos e que o resultado dessa relação é a liberdade. No comentário a esse parágrafo Hegel (1994, p. 121) diz que "Vontade sem liberdade é uma palavra vazia, assim como a liberdade só é efetiva enquanto vontade, enquanto sujeito".

Deve-se ressaltar que o entendimento de liberdade proposto por Hegel não coaduna com as ideias de liberdade que foram elaboradas pelos pensadores do liberalismo que precederam Hegel. Este não concebe liberdade somente como um fundamento de desimpedimento dos atos da vida pública ou como liberdade negativa. Em Hegel, a liberdade está ligada à ideia de vontade livre e necessita de sua real efetivação.

A vontade livre, em um primeiro momento, é somente em-si, ou seja, é um conceito imediato que não há reflexividade. Enquanto a vontade livre for somente ideia ou conceito, ela permanecerá sendo somente em-si. A partir do momento em que atinge uma instância reflexiva, a vontade livre passa a ser objeto da sua própria vontade e, portanto, passa a ser para-si. Fazendo-se valer da ideia de vontade livre, passa-se agora a explanar a primeira parte da Filosofia do Direito: o Direito Abstrato.

\footnotetext{
${ }^{7}$ Interessante é a lição de Henrique Lima Vaz (1998, p. 17) ao tratar do agir humano: "Trata-se, em suma, de repensar filosoficamente, em face das ciências do ethos como forma de cultura, o problema já reconhecido por Hegel quando definiu o Direito (entendido em sentido amplo cobrindo toda a esfera do ethos) como "realização concreta da liberdade", a saber, o problema da realização histórica, social e cultural da liberdade, que só subsiste como sendo manifestação da essência do homem ao se constituir como liberdade consensual, enraizada no terreno da Ética e do Direito". 


\subsection{Direito Abstrato 8}

É no Direito Abstrato onde estão contidos parte do que hoje chamaríamos direitos de primeira dimensão, em especial o direito à propriedade e o direito contratual; e parte do direito penal. Como primeiro movimento da vontade livre, é no Direito Abstrato onde a vontade livre é em-si e, portanto, é imediato (não há reflexividade com outras instâncias, até então).

Já no prelúdio ao Direito Abstrato, Hegel coloca a personalidade como base teórica para a primeira etapa do Espírito Objetivo. O elemento que compõe a personalidade é justamente o indivíduo concebido dentro da tradição jusnaturalista que é possuidor de direitos subjetivos, o que vai ao encontro da analogia de que comporta parte dos direitos de primeira dimensão (Cf. MÜLLER, 2005, p. 164-165). Nos termos de Hegel (2010, p. 80), “A personalidade contém, de maneira geral, a capacidade jurídica e constitui o conceito e a base, também abstrata, do direito abstrato e, por isso, formal [...]”.

É dentro dessa esfera do Direito Abstrato que o direito, enquanto instância imediata da liberdade, desdobra-se na propriedade; na passagem da propriedade de uma pessoa para outra, que desemboca no contrato; e quando a vontade resulta no ilícito. Em suma, trata-se da relação de alguém com algo (Coisa/Res). O sujeito possui algo, transmite algo por meio do contrato e toma para si algo de outrem.

É por meio da propriedade que se dá, em um primeiro momento, uma externalização da liberdade. O indivíduo domina algo na natureza e passa a tratar como seu, dando forma e

\footnotetext{
${ }^{8}$ Marcos Müller (2005, p.163-164) faz uma significativa explanação do motivo pelo qual Hegel adjetiva a primeira parte da Filosofia do Direito por "abstrato": "O direito de que trata Hegel na I" Parte da Filosofia do Direito, O Direito Abstrato, é "abstrato" em vários sentidos: 1) porque Hegel enuncia e desenvolve aí, nos termos da sua teoria especulativa do conceito de liberdade, apresentada sucintamente na Introdução à obra, somente os princípios e conceitos fundamentais do moderno direito privado e, também, do direito penal, os quais fundamentam filosoficamente o direito no sentido jurídico, mas considerado independentemente da sua respectiva positivação no Estado e da sua aplicação jurisdicional; o direito no sentido jurídico estrito é, assim, uma esfera parcial, "abstrata", do direito no sentido amplo, que é, este, co-extensivo à esfera do espírito objetivo e ao conjunto das formas de objetivação da liberdade; 2) porque, embora tenha uma "efetividade imediata", por ser objetivação primeira e mais elementar da liberdade, e embora não seja, também, apenas o ordenamento jurídico na sua validade normativa abstrata, ele é, todavia, "de início, porém, somente como um dever-ser (Sollen)" (§ 86), pois enquanto expressão da vontade racional e universal que é ainda só em si, ele é "somente algo exigido", "direito em si" (§ 87), portanto, "abstrato" no sentido de que nele a liberdade é efetiva de maneira somente "imediata"; 3) precipuamente, porque o seu princípio fundamental é a "personalidade [enquanto] contém a capacidade de direito e constitui o conceito e a base, ela própria abstrata, do direito abstrato" (§ 36): a personalidade é a vontade livre em si e para si objetivada "na determinidade da imediatez", ela é uma "efetividade que só se relaciona abstratamente a si" (§ 34) e que só tem consciência da sua liberdade enquanto "universalidade formal", que está numa "relação simples a si, na sua singularidade" (§ 35)".

CONPEDI LAW REVIEW | EVENTO VIRTUAL | v. 6 | n. 1 | p. 118 - 137 | JAN - DEZ | 2020 
determinação à sua vontade que ainda é infinita, universal e abstrata. É preciso passar a um segundo momento, à particularidade concreta, em que o sujeito, ao possuir algo, deixa de ser um ser em-si e passar a ser para-si. Destarte, a propriedade é uma dimensão existencial da personalidade, o que representa a vontade interna do indivíduo.

Ao possuir e ser proprietário de algo se tem o pleno domínio da Coisa e o destino que se dá a ela é uma esfera da liberdade. Quando alguém torna alheio aquilo que lhe pertence, há duas implicações: a primeira é a de eu passo a dar mais contornos à minha vontade; a segunda é que, ao transmitir a propriedade de algo a alguém, passa-se a reconhecer o outro como um igual sujeito e proprietário. Nas palavras de Hegel (2010, p. 106): “O contrato pressupõe que aqueles que o estabelecem se reconheçam como pessoas e como proprietários; pois ele é uma relação do espírito objetivo, assim o momento do reconhecimento já está nele contido e pressuposto (...)".

Mais importante que a transmissão da propriedade, o reconhecimento mútuo trazido pelo contrato acaba por combinar a multiplicidade de vontades de dois sujeitos diversos, o que passa de uma relação imediata da vontade para uma mediação da vontade do alienante para com o futuro proprietário. É nessa mediação de vontades em que a liberdade tem sua existência.

A terceira e última seção do Direito Abstrato trata do Ilícito e se desenvolve em três partes: o Ilícito Não-Intencional; a Fraude; e Coação e Crime. Segundo Marcos Müller (2006, p. 25):

[As três modalidade de Ilícito] correspondem a três formas de agravamento da oposição da vontade particular à universalidade em si, que é tanto a universalidade objetiva do direito, quanto a universalidade imanente à própria vontade pessoal singular. Elas se desdobram e determinam segundo uma lógica de intensificação progressiva da aparência e da sua crescente independização em face da essência, definida inicialmente, pelo conceito abstrato de direito em sua universalidade somente em si.

Tem como o Crime a personificação do Ilícito, é válido destacar os artigos 91 e 92 da Filosofia do Direito. Neles Hegel dispõe que a vontade livre não pode ser coagida, a menos que alguém queira se deixar coagir. Ao coagir ou tomar a Coisa de alguém, está se limitando a própria existência da vontade livre.

\subsection{Moralidade}


A Moralidade já foi brevemente tratada no início do presente artigo e, portanto sua exposição aqui será mais sintética. Corrobora-se com Denis Rosenfield (2010, p. 9) no que ele diz a respeito sobre a Moralidade:

O conceito hegeliano de Moralidade diz respeito ao que hoje consideramos como a
esfera subjetiva do indivíduo, o que ele denomina, nesse âmbito, de "sujeito". O
"sujeito" é aquele que se faz moralmente pelo conjunto de suas ações. Hegel toma a
ação moral enquanto núcleo central de suas considerações, tendo como norte a
dimensão subjetiva, a de intenções, convicções e projetos que se realizam
praticamente. Segundo ele, para determinar a moralidade de um "sujeito", não basta
tomar como ponto de partida a dimensão meramente subjetiva, pois, se ela não se
concretizar, não poderá ser objeto de juízo moral. Uma mera intenção - ou
poderíamos dizer uma mera fantasia -, se não se realizar, não será, propriamente,
nem boa, nem má. Numa perspectiva aristotélica, a moralidade de um sujeito
determina-se pelo seu agir.

Fica mais claro nessa passagem como a moralidade aborda de forma mais contundente a filosofia prática de Hegel e como se dá a dimensão do agir. Axel Honneth (Cf. 2007, p.92), a respeito da Moralidade, diz que se deve delinear a liberdade como uma forma de auto-relação, isto é, apenas quando alguém efetivamente reflete sobre como se deve agir é que se pode falar plenamente em liberdade individual.

A Moralidade como instância de negação do Direito Abstrato tem como sua suprassunção aquilo que Hegel vem a chamar de Eticidade. Essa passagem da Moralidade para a Eticidade se dá uma vez que a Moralidade só recebe seu conteúdo através do contraste da existência de uma sociedade inteira (Cf. TAYLOR, 2010, p. 324). Em vias de conclusão, enquanto a Moralidade está para um contexto da subjetividade moral, a Eticidade se refere ao agir dentro de uma realidade social onde adentram contextos de costumes, religião, economia e organização da vida pública.

\subsection{Eticidade}

Afunilando a filosofia prática de Hegel, é na Eticidade em que se encontram a concretização das obrigações morais e, por conseguinte, é nela que reside a própria ideia de liberdade. Nas palavras de Hegel (2010, p. 167), a "Eticidade é o conceito da liberdade que se tornou mundo presente e natureza da autoconsciência”. Ou seja, a liberdade ganha seus contornos mais firmes a partir do momento em que a vontade é confrontada com suas questões subjetivas frente à sociedade na qual o portador da vontade está inserido. 
$\mathrm{Na}$ Enciclopédia das Ciências Filosóficas é colocado que a Eticidade é o cumprimento do Espírito Objetivo e a sua liberdade se dá na exterioridade que virão a serem os três estágios nas quais se divide a Eticidade: Família, Sociedade Civil e Estado. Estas três etapas devem coexistir de maneira harmoniosa e equilibrada de forma que o seu processo de afirmação, negação e suprassunção permitam que cada estágio seja condição de existência de outro (Cf. ROSENFIELD, 2010, p. 19).

A Família é o primeiro contato que o indivíduo tem com o contexto social. Colocando de maneira mais coloquial, a Família é a unidade atômica na qual o Espírito primeiramente se manifesta, sendo um retalho da sociedade. Nos dizeres de Hegel (2010, p. 174), Família é a "substancialidade imediata do Espírito".

É por meio do casamento, da externalização e administração das suas propriedades e da educação dos filhos que se dá a realização da Família, incluindo a possibilidade de dissolução da própria família, seja por meio da morte de algum membro ou pela cessação do casamento.

O segundo estágio é intitulado Sociedade Civil $^{9}$ e alberga várias esferas da vida pública e privada e são precisamente nessas esferas onde residem as instituições tão necessárias para a realização da liberdade. Isto por que os interesses particulares do indivíduo devem ser mediatizados com os interesses de outros indivíduos e para que isso tenha realização são necessárias instâncias de mediação entre ambos.

A Sociedade Civil se desdobra em três momentos distintos: Sistema das Necessidades, que é o equivalente à economia; a Administração do Direito, que implica numa dimensão jurídico-burocrática do direito enquanto lei ou enquanto a relação para com as funções do judiciário; e a Administração Pública e Corporação ${ }^{10}$.

\footnotetext{
${ }^{9}$ Hegel usa a expressão bürgerliche Gesellschaft que, literalmente, significa sociedade burguesa. Por isso, não é raro algumas traduções trazerem como título da segunda parte da Eticidade como Sociedade civil-burguesa.

${ }^{10}$ Cabe aqui alguns esclarecimentos quanto a tradução dos termos utilizados por Hegel para os três momentos da Sociedade Civil: Das System der Bedürfnisse; Die Rechtspflege e Die Polizei und Korporation, respectivamente. Para a redação deste trabalho estão sendo usadas duas traduções da Filosofia do Direito, que podem ser consultadas na bibliografia. Ocorre que os autores tomaram a liberdade de mesclar as duas traduções especificamente no presente ponto. Portanto, o primeiro momento (Das System der Bedürfnisse) optou-se pela expressão Sistema das Necessidades por dar conotação mais imediata à questão da escassez, que é uma das problemáticas centrais da economia. O segundo momento (Die Rechtspflege) as duas traduções concordam com o uso da expressão "Administração do Direito". Por fim, discorda-se de Marcos Müller quando se traduziu Polizei und Korporation por "Polícia e Corporação". Essa parte da Sociedade Civil trata da CONPEDI LAW REVIEW | EVENTO VIRTUAL | v. 6 | n. 1 | p. 118 - 137 | JAN - DEZ | 2020 
É relevante destacar que a Sociedade Civil em Hegel é uma resposta à dimensão de liberdade que foi dada pela Revolução Francesa, a saber, ter a liberdade enquanto forma política institucionalizada na sociedade. Com a derrubada do ancien régime, a estrutura engessada da sociedade feudal e absolutista dá lugar ao desenvolvimento das potências do indivíduo em várias frentes, seja ela pelas necessidades que surgem por uma nova divisão social do trabalho, seja por uma nova forma de organização da organização do direito e da justiça (vide o movimento das codificações que tiveram início sob o vaticínio napoleônico, tanto na França quanto na Alemanha com seus respectivos Códigos Civis). A estrutura da administração pública também ganha novas formas a partir do momento em que ela passa a ser uma entidade cujo propósito é assegura a ordem pública, especificamente zelar pela propriedade e pela personalidade (Cf. MÜLLER, 2000, p. 6-7).

Por fim encontra-se o Estado que é onde se dá a suprassunção da Eticidade. É no Estado que se dá a efetividade da ideia ética e da vontade substancial uma vez que é nele que se alcança o patamar de universalidade da autoconsciência particular (Cf. HEGEL, 2010, p. 230).

Os três momentos do Estado tem correlação imediata com os novos desenhos institucionais que a Europa e a Alemanha vêm tomando. Hegel (2010, p. 234) dispõe que a ideia de Estado tem, primeiramente, uma "efetividade imediata, e é o Estado individual enquanto organismo que está em relação consigo, - constituição ou direito estatal interno" (grifos do autor). Depreende-se a ideia de Estado cujo horizonte era a constitucionalização da organização dos principados que compunham a Alemanha à época. Isso dá pela passagem da Sociedade Civil para o Estado, visto que é necessário um aparato institucional e burocrático para que se desse essa nova organização.

A ideia de Estado também "passa à relação do Estado singular com outros Estados, direito estatal externo" (HEGEL, 2010, p. 234), no qual, uma vez em que o Estado já tem capacidade para se autodeterminar, ele passa a buscar formas para se relacionar com outros Estados como iguais. Aqui se pode fazer uma analogia com o momento do contrato que está situado no Direito Abstrato, uma vez que o indivíduo passa a alienar sua propriedade para

administração pública e o termo "Polizel" pode ser entendido como uma instituição da administração pública. Portanto, optou-se por utilizar a tradução da Editora Unisinos, a saber, "Administração Pública e Coorporação".

CONPEDI LAW REVIEW | EVENTO VIRTUAL | v. 6 | n. 1 | p. 118 - 137 | JAN - DEZ | 2020 
outrem e, consequentemente, toma-se o outro como igual sujeito de direito. É da relação entre os Estados que se dá o motor da história no mundo.

\begin{abstract}
Na relação dos Estados uns frente aos outros, porque eles estão aí como particulares, entra o jogo extremamente móvel da particularidade interna das paixões, dos interesses, dos fins, dos talentos e das virtudes, da violência, do ilícito e dos vícios, assim como o da contingência externa nas maiores dimensões do fenômeno, - um jogo no qual a totalidade ética mesma, a autonomia do Estado, está exposta à contingência. (HEGEL, 2010, p. 305).
\end{abstract}

E é por meio dessa negação e afirmação entre os Estados que se dá a história mundial e, consequentemente, em que se dá a efetividade do Espírito. É nesse movimento reflexivo que os Estados vão dando impulso à história e perquirindo seu progresso. Hegel se faz valer de quatro exemplos do que ele chamou de reinos histórico-mundiais para mostrar esse impulso: reino oriental, grego, romano e germânico.

Vê-se, pois o otimismo de Hegel ao ver como os idos da Revolução Francesa foram o móbil que está levando o progresso institucional e, por conseguinte, a liberdade ao contexto em que ele está inserido, o Alemão.

\title{
CONCLUSÃO
}

Mais a guisa de considerações finais que para o encerramento como conclusão, buscou-se na pesquisa ora intentada esboçar de maneira mais sintética como opera epistemologicamente o sistema filosófico elaborado por Georg. W. F. Hegel, atendo-se ao seu principal mote, a liberdade, e vendo como o direito tem sua participação em meio a esse robusto projeto.

Sabendo-se da impossibilidade de esgotar o tema, verificou-se como liberdade figura no proscênio da modernidade que é inaugurada com a Revolução Francesa, ponto de inflexão da história para Hegel.

Indo além do conceito de liberdade negativa, a ideia de liberdade em Hegel repousa nas instituições que foram trazidas sob os auspícios da Revolução Francesa, bem como na mudança da estrutura social.

O direito, conforme fora mencionado, tem um papel preponderante uma vez que ele vez a ser o solo da liberdade efetivada, pois é nele que a vontade livre consegue se CONPEDI LAW REVIEW | EVENTO VIRTUAL | v. 6 | n. 1 | p. 118 - 137 | JAN - DEZ | 2020 
desenvolver. Direito Abstrato, Moralidade e Eticidade são os momentos pelos quais o Espírito passa para efetivar a liberdade.

Trazendo para o contexto contemporâneo, Hegel nos é importante ao mostrar a relevância das instituições para a liberdade e, no nosso caso, para a manutenção do estado democrático de direito. Mesmo com os déficits que os períodos totalitários acarretaram, foi com as instituições surgidas na modernidade que se conseguiu firmar ideais de democracia e inclusão, mesmo que a passos pequenos a bem da verdade.

Hegel, portanto, ainda merece ser lido, não só por sua retumbante relevância teórica que serviu como divisor de águas para as Ciências do Espírito, para usar o termo cunhado por Wilhelm Dilthey, e ainda fornece elementos para melhor compreensão da sociedade contemporânea, e seu aniversário de 250 anos é um oportuno ensejo para que sua obra seja rememorada.

\section{REFERENNCIAS}

BUCK-MORSS, Susan. Hegel e Haiti. Novos Estudos - Cebrap, [s.1.], n. 90, p. 131-171, jul. 2011. FapUNIFESP (SciELO). http://dx.doi.org/10.1590/s0101-33002011000200010. Tradução de Sebastião Nascimento.

HABERMAS, Jürgen. O discurso filosófico da modernidade: doze lições. São Paulo: Martins Fontes, 2000. Tradução de Luiz Sérgio Repa e Rodnei Nascimento.

HEGEL, Georg Wilhelm Friedrich. Enciclopedia de las Ciencias Filosóficas en Compendio. Madrid: Alianza Editorial, 2005. Tradução de Ramón Valls Plana.

HEGEL, Georg Wilhelm Friedrich. Fenomenologia do Espírito. Petrópolis: Vozes, 1992. Tradução de Paulo Menezes.

HEGEL, Georg Wilhelm Friedrich. Linhas fundamentais da filosofia do direito ou direito natural e ciência do Estado em compêndio (1820): Introdução (\$§ 1-33). Analytica, Rio de Janeiro, v. 1, n. 2, p. 107-161, 1994. Tradução de Marcos L. Müller. Disponível em: https://revistas.ufrj.br/index.php/analytica/article/view/646/601. Acesso em: 22 abr. 2020.

HEGEL, Georg Wilhelm Friedrich. Linhas fundamentais da filosofia do direito ou direito natural e ciência do Estado em compêndio: Terceira parte - A Eticidade; Segunda lição - A Sociedade Civil. Textos Didáticos, Campinas, v. 1, n. 21, p. 5-101, 2000. Tradução de Marcos L. Müller. 
HEGEL, Georg Wilhelm Friedrich. Linhas Fundamentais da Filosofia do Direito: ou direito natural e ciência do estado em compêndio. São Leopoldo: Editora Unisinos, 2010. Tradução de Paulo Menezes et. al.

HEGEL, Georg Wilhelm Friedrich. Phenomenology of Spirit. Oxford: Oxford University Press, 1977. Tradução de A. V. Miller.

HONNETH, Axel. Sofrimento de indeterminação: uma reatualização da Filosofia do direito de Hegel. São Paulo: Editora Esfera Pública, 2007. Tradução de Rúrion Soares Melo.

HORSTMANN, Rolf-peter. What is Hegel's Legacy and what should we do with it? European Journal of Philosophy, [s.1.], v. 7, n. 2, p. 275-287, ago. 1999. Wiley. http://dx.doi.org/10.1111/1468-0378.00087.

MÜLLER, Marcos Lutz. Apresentação da tradução da Sociedade Civil. Textos Didáticos, Campinas, v. 1, n. 21, p. 5-13, 2000.

MÜLLER, Marcos Lutz. O direito abstrato de Hegel. Um estudo introdutório (primeira parte). Analytica, Rio de Janeiro, v. 9, n. 2, p. 161-197, 2005. Disponível em: https://revistas.ufrj.br/index.php/analytica/article/view/513/468. Acesso em: 22 abr. 2020.

MÜLLER, Marcos Lutz. O direito abstrato de Hegel. Um estudo introdutório (segunda parte). Analytica, Rio de Janeiro, v. 10, n. 1, p. 11-41, 2006. Disponível em: https://revistas.ufrj.br/index.php/analytica/article/view/514/469. Acesso em: 22 abr. 2020.

PLANA, Ramón Valls. La Enciclopedia en la vida y obra de Hegel: presentación del traductor. In: HEGEL, Georg Wilhelm Friedrich. Enciclopedia de las Ciencias Filosóficas en Compendio. Madrid: Alianza Editorial, 2005. p. 11-37.

ROSENFIELD, Denis Lerrer. Apresentação da tradução e da atualidade da Filosofia Do Direito De Hegel. In: HEGEL, Georg Wilhelm Friedrich. Linhas Fundamentais da Filosofia do Direito: ou Direito Natural e Ciência do Estado em Compêndio. São Leopoldo: Editora Unisinos, 2010. p. 5-22.

TAYLOR, Charles. Hegel. Barcelona: Anthropos Editorial, 2010. Tradução de Francisco Castro Merrifield, Carlos Mendiola Mejía e Pablo Lazo Briones.

VAZ, Henrique C. de Lima. Antropologia Filosófica I. São Paulo: Edições Loyola, 1998.

VAZ, Henrique C. de Lima. Escritos de Filosofia IV: Introdução à Ética Filosófica 1. São Paulo: Edições Loyola, 1999. 